\title{
CONDICIONES PARA EL NACIMIENTO DE LA CIENCIA FICCIÓN ESPAÑOLA CONTEMPORÁNEA
}

\section{Conditions for the Born of the Recent Spanish Science Fiction}

\author{
Fernando Ángel MORENO, Mikel PEREGRINA y Steven BERMÚDEZ \\ Universidad Complutense de Madrid y Universidad del Zulia
}

Spanish science fiction had a very good period in the decades prior to the Civil War. We wouldn't find a similar interest until the seventies and the eighties. To start with, this was due to the New Dimension magazine and subsequently many factors contributed to the appearance of several interesting writers that, especially with their short stories, provided the best works until nowadays.

El presente trabajo expone los numerosos factores -editoriales, sociales, políticos y técnicos - que influyeron en el auge de la ciencia ficción española durante los años ochenta. La enorme complejidad de esta realidad histórico-literaria aporta claves para el entendimiento del desarrollo del género en España y, en general, para abrir nuevas vías de análisis de la literatura española de la segunda mitad del siglo XX.

\section{Introducción}

La literatura de ciencia ficción española apenas ha sido atendida por la academia. ${ }^{1}$ Sin embargo, su estudio ahonda en el entendimiento de los fenómenos literarios y, más concretamente, en el del desarrollo social y estético de la literatura en España. En esta línea, este trabajo forma parte de un proyecto más amplio que estudia el auge del género en España entre 1985 y $2000 .^{2}$ Aquí exponemos los resultados de una de las muchas líneas abiertas.

Para esta investigación, hemos seguido propuestas de diversos teóricos de la historia de literatura, especialmente las propuestas de Valdés y Greenblatt, a través de las diversas críticas a la obra de Michel Foucault (Escrig, 2005: 32). En este sentido, no estableceremos relaciones jerárquicas de análisis histórico, sino confluencia de factores de influencia heterogénea; sincrónica y diacrónica. Por ejemplo, Valdés agrupa estos factores en nudos de interacción entre autores, obras y nuevas interacciones de los propios nudos entre sí, en detrimento de la tradicional búsqueda de

\footnotetext{
${ }^{1}$ La mayor parte de los estudios sobre ciencia ficción española contemporánea han sido publicados en EE.UU. Como monografías más o menos interesantes, tenemos el libro de Molina-Gavilán y la ligera aportación de Florence Behm. En cuanto a artículos sobre aspectos concretos, destacamos los trabajos de Genara Pulido Tirado y Dale Knickerbocker. Respecto a la historia del género en España disponemos de los breves estudios de Díez y el de Moreno (2010: 407-436), además de su estudio en Cátedra (Díez y Moreno, 2014). En la academia española, apenas se ha estudiado nuestra ciencia ficción y a menudo se debe recurrir a webs no científicas para encontrar información pertinente, como el blog de Juan Manuel Santiago, Pornografía emocional.

2 Debemos agradecer para la elaboración de este artículo la ayuda de Julián Díez, quien no solo permitió el acceso a su biblioteca privada, sino que arrojó importante luz sobre el pasado del género en España y aportó matices esenciales para el trabajo. También agradecemos la ayuda de escritores, editores y aficionados como Santiago L. Moreno, Mariano Martín Rodríguez, Rafael Marín, Manuel Barrero, Juan Miguel Aguilera, Eduardo Vaquerizo y Alfredo Álamo.

Este artículo forma parte del proyecto de investigación FFI2011-28226, financiado por el Ministerio de Ciencia e Innovación de España en 2011: Historia de la ciencia ficción española (1985-2000).
} 
ejemplos macrohistóricos determinantes o de férreos esquemas de influencia, como ya criticara Claudio Guillén.

De este modo, ante una situación que encuentra sus primeros elementos de influencia destacada en la segunda mitad de los setenta y principios de los ochenta, habría resultado sencillo suponer que el clima de la transición, a partir de la muerte del dictador Francisco Franco, aglutinó las condiciones necesarias para un cambio en la producción y recepción de la literatura fantástica. Sin embargo, el estudio de los nudos geográficos, temporales, institucionales y formales (Valdés, 2002:137) revela que el clima político no influyó tanto como cabría suponer en un primer momento.

\subsection{La ciencia ficción más relevante}

Ante todo, cabe señalar que la literatura de cf ha sorprendido a quienes se han acercado a ella con rigor y desprovistos de prejuicios. En sus filas encontramos autores de la talla de Kurt Vonnegut Jr., Ursula K. Le Guin o Stanislaw Lem, por citar a los más reconocidos. ${ }^{3}$ Pese a la gran cantidad de obras mediocres, el género cuenta con narraciones complejas y de gran valor literario, como The Left Hand of Darkness (Le Guin, 1969), Crash (Ballard, 1973), Solaris (Lem, 1961) o The Road (McCarthy, 2006), entre cientos.

Especialmente reseñable es su periodo de mayor experimentación literaria, la New Wave desarrollada de los años sesenta y setenta, con escritores como Brian Aldiss, Samuel R. Delany, Michael Moorcok o el citado J.G. Ballard. Estos autores desarrollaron planteamientos ya apuntados a finales del siglo XIX y en la primera mitad del siglo XX por escritores como Evgueni Zamiatin, H.G. Wells, Aldous Huxley o George Orwell, entre otros. Para ello fundieron el aspecto especulativo e intelectual de las propuestas con complejos y arriesgados experimentos literarios.

Paralelo a este discurso, se desarrollaba en occidente la cf del pulp, más centrada en héroes con taparrabos que desbarataban invasiones extraterrestres o planes de científicos locos, con el apoyo de una guapa chica gritona y continuamente en peligro. Este tipo de ficción, extendida al cine desde los años cincuenta, creó el conjunto de prejuicios por el que ha sido injustamente medida. Nuestro país no resultó ajeno a esta disputa, ${ }^{4}$ como también la aparición del pequeño gueto que analizamos a continuación continuó en parte algunas de estas tendencias anglosajonas. ${ }^{5}$

\subsection{Los nudos}

Los nudos propuestos por Valdés remiten a una serie de elementos que interaccionan en muy diferente medida según el autor y la obra. Así, establece los cuatro nudos mencionados: geográficos, temporales, institucionales y formales. Nosotros lo completamos con las propuestas de Lotman sobre la semiosfera, especialmente fructíferas en el caso de la cf española, y con la perspectiva relativista de H.R. Jauss en cuando a reivindicación de lo externo al canon, la construcción socio-cultural de la literatura y los horizontes de expectativas que esta literatura generaría.

En este sentido, contemplamos la literatura española de cf comprendida entre 1985 y 2000 como una semiosfera delimitada por el nudo temporal propuesto. La fecha de inicio está escogida como punto intermedio entre las publicaciones de las dos obras más representativas del periodo: Lágrimas de luz (Marín, 1982) y Mundos en el abismo (Aguilera y Redal, 1988). La final representa un cierre simbólico que coincide aproximadamente con el auge de internet y la decadencia de las revistas especializadas.

Como nudos geográficos, aparecen las convenciones y las tertulias de diferentes ciudades, que se funden con ciertos nudos institucionales como la Asociación de Fantasía, Ciencia Ficción y Terror

\footnotetext{
${ }^{3}$ Citando un ejemplo mediático de reconocimiento, Harold Bloom los recomienda en El canon occidental (1994: 563-564, 570571).

${ }^{4}$ La influencia del cine y del pulp literario ha ocupado otra línea de investigación cuyos resultados presentaremos en otro artículo. Para introducirse en el cine español de ciencia ficción, disponemos del estudio de Sánchez-Conejero.

${ }^{5}$ Seguimos, en este sentido, la perspectiva de Roger Luckhurst, a partir de estudios culturales.
} 
o ciertas "élites" críticas que renegaban explícitamente de la cultura oficial. Estos factores llevaron al establecimiento de un gueto, con repercusiones culturales positivas y negativas.

Como nudos culturales, nos encontramos con dos hechos fundamentales: la aparición de fanzines y el ambiente experimental de cierta España de los años setenta y ochenta.

Con todo ello, esperamos arrojar una nueva perspectiva sobre la historia de la literatura y de la cultura españolas de los ochenta y los noventa.

\section{Nudo temporal-institucional: La generación de los noventa o «generación hispacón»}

En 1982, un joven filólogo, Rafael Marín, publicaba Lágrimas de luz, una novela de estructura polémica $^{6}$, con reminiscencias de la novela de aventuras ${ }^{7}$. Su mayor originalidad se basaba en la evolución melancólica y decadente del ánimo del héroe. A esto se le unían numerosas referencias estilísticas y temáticas a la literatura clásica española, desde su narrativa medieval hasta sus Siglos de Oro.

Ya existían ejemplos semejantes de dignificación estilística y referencial del género en España, como algunas novelas de Pedro Salinas (1951), Tomás Salvador (1959) o Gabriel Bermúdez Castillo (1976), así como numerosos cuentos de autores tan inesperados como Luis Antonio de Villena (1978) o Mariano Antolín Rato (1981) o incluso poemas de Luis Eduardo Aute (1982). No obstante, la trascendencia de Lágrimas de luz se debe a que numerosos escritores posteriores la consideraron un modelo a seguir y una demostración de que podía escribirse y publicarse en España cf más digna que la publicada hasta entonces. Al fin y al cabo, se trató solo de la punta del iceberg de un interés escondido, aunque apasionado, por los cuentos de cf. ¿Por qué, en cierto momento, a ciertos escritores les resultaba más sencillo acercarse a un género "menor" como la cf que a otros géneros? ¿Por qué los cuentos de cf gozaban de esta popularidad? ¿Por qué, si tantas ventas tuvieron, este hecho no ha sido estudiado hasta ahora?

Podemos afirmar que existió una avanzadilla de la nueva generación, a principios de los años setenta, reseñable por sus logros estéticos y su influencia posterior: la segunda mitad de los años setenta vivió un crecimiento considerable del interés por el género (Samaniego, 1978). ${ }^{8} \mathrm{La}$ constatación de este creciente interés llegaría primero en 1988, con la publicación de una ambiciosa space opera: ${ }^{9}$ Mundos en el abismo. Sin embargo, al contrario que los escritores de bolsilibros que habían frivolizado tanto con la space opera, los autores de esta propuesta eran ingenieros y biólogos de excelente formación y largas lecturas, de nuevo desde la New Wave. En ella, Juan Miguel Aguilera y Javier Redal describían razas alienígenas y aeronaves con el máximo rigor científico, al tiempo que trazaban una complicada estructura política y religiosa con personajes ambiguos. No se trataba de una obra a la altura de los grandes clásicos de la literatura mundial, pero sí suponía un enorme salto cualitativo respecto a los bolsilibros (Díez, 2003: 17-9), que animó a otros jóvenes escritores.

Al poco tiempo, encontraríamos la aparición de pequeñas obras maestras como "El rebaño", de César Mallorquí (1993), o "La estrella", de Elia Barceló (1991), bajo la fuerte influencia de la New Wave, quienes se centraron en el género al descubrir que sus relatos eran publicados y elogiados.

Así, desde principios de los noventa, y aparentemente animados por este reconocimiento, surgieron numerosas revistas y colecciones de ciencias ficción, y florecieron las convenciones de aficionados y las tertulias en numerosas ciudades españolas.

La influencia de Star Wars, estrenada en España en 1977, pudo existir, ¿qué duda cabe? Sin embargo, la manera en que se desarrolló el género en el mundo anglosajón a raíz de la película no coincide en demasiados puntos con la manera en que se desarrolló en España. Apenas se tomaron

\footnotetext{
${ }^{6}$ Su construcción episódica arrastra, en nuestra opinión, irregularidades estilísticas y narrativas.

${ }^{7}$ El propio Rafael Marín insiste en esta visión de la obra en la entrevista realizada por Sánchez-Conejero (2009: 238).

${ }^{8}$ Como puede verse en la prensa de la época, en la referencia anónima de 1978 incluida en la bibliografía.

${ }^{9} \mathrm{La}$ space opera es el género más conocido de la ciencia ficción. Suele desarrollar aventuras heroicas con largos viajes espaciales y mundos alienígenas; ver Sawyer.
} 
elementos de las películas producidas por Lucas, al contrario que en el mundo anglosajón (Luckhurst, 2005:168). Si deseamos rastrear la influencia, la encontraremos mucho más en los relatos de la New Wave que en las maniqueas aventuras galácticas o en los efectos especiales.

Así, casi todas las novelas de este periodo, hasta el año 2000, mostraron tanto interés por un discurso literario muy elaborado como por las tramas complejas y los personajes anti-heroicos, desarrollados desde cierto intimismo. Quizás los resultados no fueron siempre modélicos, pero se construyó una extensa e intensa red literaria con seguimiento y productividad sin parangón en la literatura española de la época, pese a su escasa repercusión externa.

Iniciaron así su carrera León Arsenal, Daniel Mares, Rodolfo Martínez, Eduardo Vaquerizo, Armando Boix, Ramón Muñoz o Joaquín Revuelta, con los citados Elia Barceló, César Mallorquí, Juan Miguel Aguilera y Rafael Marín. Todos ellos publicaron antologías y novelas con buenas críticas en revistas especializadas y muchos han continuado publicando sin altibajos, aunque pocos hayan sido reconocidos más allá de las fronteras genéricas.

\section{Nudos formales e institucionales: La entrada de la ciencia ficción en España: antologías y experimentos}

Aunque pudiéramos pensar que la cf es un género exclusivamente posmoderno, las novelas de utopías y distopías — así como las de viajes por el tiempo y el espacio - fueron muy populares a finales del siglo XIX y principios del XX. No obstante, apenas influyeron en la contemporánea, pues el corte producido por la Guerra Civil Española truncó el desarrollo del género en España. Para este periodo remitimos a los trabajos de Mariano Martín Rodríguez (2009a, 2009b y, especialmente, 2010).

A mediados de los años cincuenta se produjo una súbita recuperación. Por un lado, aparecieron los bolsilibros, ${ }^{10}$ arropados por películas de serie B como The Day the Earth Stood Still (Wise, 1951), The Thing from Another World (Nyby, 1951), Them! (Douglas, 1954) o Invasion of the Body Snatchers (Siegel, 1956). Pero estas producciones fílmicas apenas influyeron más adelante, como veremos.

Por otro lado, algunas editoriales comenzaron a publicar traducciones de buenos relatos y, menos habitualmente, de novelas de cf anglosajona. Por lo general, no se prestaba gran atención a los textos y a menudo se producían incluso mutilaciones y serias transformaciones de ellos. Además, el formato y las cubiertas mantenían durante los cincuenta y los sesenta la línea del pulp y de sus primos hermanos, aquellos bolsilibros. Sin embargo, no dominaba el pulp. Por el contrario, se confiaba en la calidad, en la innovación y en la relevancia literaria que aquellos relatos estaban consiguiendo en EE.UU. y Gran Bretaña. ${ }^{11}$

Desde los años cincuenta hasta 1968, se produjo un enorme éxito en la publicación de antologías de relatos anglosajones. No solo nos encontramos con varias colecciones a nivel nacional, sino que incluso de algunas ellas aparecen incluso varias ediciones como las de 1964, 1965 y 1966.

La verdadera explosión tendría lugar en los años sesenta, con lo cual se desdicen ampliamente dos viejos mitos de la historia de la literatura española: que durante el siglo XX interesaba sobre todo

\footnotetext{
${ }^{10}$ Los bolsilibros, también conocidos como "novelas de a duro", eran novelas escritas con sorprendente rapidez y escasas aspiraciones literarias para un disfrute insustancial. Ni autores ni editores ni lectores las tenían en alta consideración (Merelo, 2001: 11; Canalda y Cantero, 2002b: 97; Vera, 2002: 179, Caballer, 2002: 202). Superaron los 4000 títulos diferentes desde 1953 hasta 1983, año en que desapareció la última colección etiquetable de este modo; ver Tarancón (2002). Los propios autores desconocían la existencia de "esa otra ciencia ficción", la de gran calidad y experimentación literaria (Canalda y Cantero, 2002a: 70).

11 Este sería uno más entre muchos síntomas que ha lastrado el género como "literatura de ideas" (Le Guin, 1989: 40). Si bien, estas ideas han sido el motor impulsor de su razón de ser, confundir esta prerrogativa con una exclusividad, en demérito de lo literario, provocó y sigue provocando problemas como estos.
} 
el realismo y que casi todo el interés por lo "no realista" o "proyectivo" (Moreno, 2010: 80-4) se limitaba a los bajos niveles de calidad de los bolsilibros. ${ }^{12}$

Muchos de los relatos presentados en estas antologías eran pequeñas obras maestras, a menudo sumamente complejas y experimentales. Los lectores premiaban su publicación con un seguimiento fiel. Existía hambre por lo proyectivo en España, como demostraban los cortos plazos para las traducciones. Por ejemplo, Acervo publicó una antología de "Lo mejor de la ciencia fícción anual" en 1970, cuando esta había sido publicada en su país de origen en 1968. Y se reeditaba.

No obstante, las grandes novelas del género, como The Man in the High Castle (1962), Dune (Herbert, 1965) o Tiger, Tiger (Bester, 1956), que encumbrarían a sus autores, verían muy retrasada su publicación en España (Canalda y Cantero, 2002a: 70). Uno de los motivos de esta diferencia entre la sincronía de los relatos y el desfase de las novelas es una clave para entender ciertas diferencias en el desarrollo de la literatura durante el siglo XX en España. En EE.UU. existía una larguísima y rica tradición de lectura de relatos en revistas periódicas. Esto propició la profesionalización de muchos escritores (Mendlesohn, 2009: 52-3). Desde los años cuarenta hasta bien avanzados los sesenta (e incluso, menos intensamente, hasta la actualidad), abundaban las revistas de relatos de cf, como Amazing Stories o Astounding Science Fiction. Así se permitió a los autores que se dedicaran a tiempo completo a la escritura, con lo que desarrollaron técnicas y una profunda interacción entre ellos y con los aficionados como ningún otro género.

Pero no en todos los países existía este mercado. En países como España, poblaciones más pequeñas impedían que el porcentaje de interesados pudiera sostener tantas publicaciones periódicas. Además no existía esta pasión estadounidense por los cuentos, así que pasarían muchos años antes de que una revista de relatos tuviera cierta repercusión. ${ }^{13}$ En definitiva, estas publicaciones apenas cuajaron en España. Sin embargo, en formato de libro, gozaron del favor del público.

¿Y qué ocurría con los autores españoles? Con el éxito de estas colecciones, comenzaron también a aparecer en antologías. Por ejemplo, la número VII de Acervo, de 1967, abrió con ocho relatos de Francisco Lezcano Lezcano, autor de quien encontramos cuentos publicados hasta los últimos años de 1979. Si bien no parecen tan interesantes como los cuentos de Disch, Zelazny o Brunner con los que compartió periodo, exhibe resulta evidente una búsqueda experimental, muy alejada de pulp y bolsilibros. Ya había en España quien concibiera el género como un campo de gran potencialidad estética. Es muy normal entre los autores españoles que encontramos en estas antologías un claro rechazo de los tópicos cinematográficos y una búsqueda en las posibilidades de las palabras, de las fuentes tipográficas y de las estructuras narrativas, aunque con resultados irregulares. Ninguno de ellos salió de las publicaciones del género.

Cabe destacar que editoriales que apostaban por este formato apenas se aventuraron a la publicación de historias más extensas. Por ejemplo, Bruguera, que aportó una colección de cuarenta antologías entre 1971 y 1979, no se arriesgaría con una colección de novelas hasta 1976.

El motivo quizás se encuentre en la propia naturaleza estética del género, considerado a menudo como "literatura de ideas". Es decir, una inquietud cultural, social, filosófica... interesa si es tratada desde la distancia de un personaje alienígena o de una sociedad alternativa. Con una pequeña peripecia y unas gotas de crítica cultural, puede impresionarse al lector sin necesitar el desarrollo de una trama que, incluso, podría despistar del tema principal. Por este motivo, la novela no sería el formato dominante del género en el mundo anglosajón hasta bien entrados los años sesenta, cuando los autores de la New Wave necesitaron de más amplios recorridos para desarrollar sus obsesiones.

La cf es, ante todo, un género de relatos cortos.

\footnotetext{
${ }^{12} \mathrm{Ha}$ llegado el momento, sin embargo, por romper una lanza por estos bolsilibros. Pese a sus evidentes limitaciones fueron el refugio de toda una generación de españoles a los que permitían evadirse de la fría realidad durante unas horas de la fría realidad. Además, sus escritores fueron auténticos profesionales, a veces con mayor talento que el que las circunstancias les permitían demostrar.

${ }^{13}$ La mayor parte de las revistas españolas fueron, incluso durante los ochenta y noventa, revistas con cuentos, más que revistas de cuentos.
} 
No obstante, en España apenas existió mercado para los escritores de cuentos más allá de estas antologías. E incluso existía un cierto rechazo hacia los escritores españoles de cf, por lo que estos debían utilizar seudónimos anglosajones (Canalda y Cantero, 2002b: 104-5). Incluso, en algunos casos, firmar con sus propios nombres habría implicado su persecución política o un automático rechazo por algún pasado republicano (Merelo, 2001: 12).

Ni existían grandes dividendos en España para el mercado del cuento ni se veía factible saltar de este campo al gran mercado literario. A los escritores españoles que preferían desarrollar una mayor complejidad poética en sus obras no les valía la pena escribir cf, por muy leída que fuera, así que vendían mucho más los relatos anglosajones.

Es cierto que se publicaron en España numerosas novelas de la llamada "Edad de Oro" de la cf anglosajona. Así, los españoles dispusieron desde muy pronto de casi toda la narrativa de Isaac Asimov, Arthur C. Clarke o Robert A. Heinlein, entre otros. No obstante, pese a lo mucho que se disfrutaban, la opinión pública no las equiparaba en ningún caso con autores como Dos Passos, Hemigway o Fitzgerald, a menudo con razón (Canalda y Cantero, 2002a: 79; Barberán y Gimeno, 2002: 165-7, 169; Vera, 2002: 192). La New Wave estaba lejos y las distancias y los tiempos eran mucho más extensos en aquellos años. Un editor podía arriesgarse con una antología de cuentos de una revista de tirada reiteradamente exitosa, pero apostar por una novela no era lo mismo.

Pero fueron pasando los años, fue disminuyendo el franquismo y se entró en las curiosas condiciones de los inquietos años setenta.

\section{Nudos formales e institucionales: La consolidación, del cuento a la novela. Antologías, fanzines, saldos y Nueva Dimensión. Y lectores.}

\subsection{El retraso de las novelas de la $\mathrm{New}$ Wave y el caos de los saldos}

Algunas editoriales publicaron traducciones de novelas de cf a lo largo de los años sesenta centrándose, sobre todo, en autores de la Edad de Oro anglosajona y en obras menores de escritores más jóvenes. La principal apuesta fue la colección Nebulae de Edhasa, desde 1954, pero cerraría en 1969 sin haber publicado novelas de gran fama. Aunque publicó algunas obras excelentes y pudo presumir de buen catálogo, no llegó a la altura ni a la sincronía de colecciones posteriores. Sin embargo, debió de influir positivamente que se publicaran ya entonces importantes novelas como The Whole Man (Brunner, 1964) o The City and the Stars (Clarke, 1956).

Los años setenta marcaron un gran cambio. Entre 1969 y 1974 se produjo un considerable descenso en la traducción de cf extranjera en España. Así, las grandes novelas escritas entre 1965 y 1975, incluidas las primeras de la New Wave, tardaron en entrar en el mercado español. Son significativos casos como el de Dune, de Frank Herbert, de 1965, que no vería su edición española hasta 1975; o el de Ubik (Dick, 1969), que tuvo que esperar siete años para su traducción, o el ya triste ejemplo de una novela tan importante para el género de la ucronía como The Man in the High Castle (Dick, 1962), que esperó hasta 1974. Se puede decir que el Dick novelista de mayor calado empezó a publicarse a mediados de los setenta, aunque ya se conocieran algunas novelas menores suyas como Solar Lottery (Dick, 1955), traducida en 1960.

$\mathrm{Si}$ acudimos a autores no anglosajones, la situación fue mucho peor. Una figura tan relevante como el polaco Stanislaw Lem no vería publicada sus Dzienniki gwiazdowe (1957) hasta 1978 y su Solaris (1961) hasta 1978. El Picnic na obochine (1977) de los hermanos Strugatski no tuvo edición española hasta 2001. ${ }^{14}$

Por si fuera poco, las traducciones eran de dudosa calidad, por decirlo de un modo suave, con supresiones de párrafos enteros o alteraciones demasiado significativas del original. Las nuevas traducciones reflejan estos cambios.

\footnotetext{
14 A pesar de que tanto Solaris como Pícnic junto al camino disfrutaron de célebres adaptaciones cinematográficas por parte de Andréi Tarkovski en 1972 y 1979, respectivamente; aunque la segunda, con el título Stalker, puede considerarse más una inspiración que una adaptación (Mengs, 2004: 19).
} 
Por consiguiente, la gran revolución novelística que tuvo lugar en la cf estadounidense a mediados de los sesenta no llegó a España hasta diez años después, como poco.

¿Y qué escribían los españoles en aquel momento? La situación era peor, incluso. En 1976 se publica la primera novela de cf española contemporánea con influencia explícita del género anglosajón, dentro de una colección especializada y con ambiciones literarias: Viaje a un planeta $W u$-Wei, de Gabriel Bermúdez Castillo. ${ }^{15}$

En 1974 apareció la colección Acervo y en 1975 la nueva colección Nebulae (Díez, 1999a y 1999c), que marcarían el verdadero éxito de la novela de cf en España, junto a las posteriores Minotauro (en su versión española), Orbis y Ultramar (Díez, 1999d y 2000a).

Sin embargo, el gran cambio no fue la repentina explosión de colecciones de cf, sino un fenómeno local: la tradición de los saldos.

La publicación de ef en España ha sufrido una rutina pendular a lo largo de los años, con crecimiento de colecciones, saturación del mercado y saldos, ciclo que ha venido repitiéndose desde los ochenta. Casi todas las grandes colecciones de género saldaron sus títulos en un momento u otro. Esto beneficiaba sobre todo a los estudiantes, tanto de secundaria y bachillerato como universitarios. Se trataba además de las edades más frecuentes para iniciarse en la cf, por lo que los saldos de Martínez Roca, Edhasa, Miraguano, Ediciones B, Ultramar..., permitían obtener repentinamente excelentes títulos a precios insignificantes. La mayor parte de los escritores y críticos españoles de cf reconocen que deben mucho a este fenómeno y que pudo influir en que se saltara tan repentinamente del cuento a la novela.

No obstante, esta irregularidad no fue la característica principal de los cuentos, género que mantendría cierto interés hasta el siglo XXI. Entonces la popularización de internet provocó la desaparición de las publicaciones periódicas impresas de cf en España.

\subsection{El éxito oculto de los cuentos anglosajones: las antologías}

Sin extendernos demasiado en cuestiones teóricas, recordemos que el efecto de extrañamiento de la $\mathrm{cf}^{16}$ permitía cumplir las expectativas en pocas páginas. Por el contrario, géneros como la novela histórica pueden precisar, con muchas páginas, la plasmación de rigurosas investigaciones. Por el contrario, para el desarrollo de una sociedad ficticia pueden bastar algunos detalles que, a partir de ciertos puntos de indeterminación, ${ }^{17}$ permitan completar el mundo propuesto.

Por otra parte, se trata de un género que permitía al editor español seleccionar lo mejor y en las dosis que considerara oportuno, entre cientos de cuentos anglosajones que se publicaban cada año. Así, durante todos los años sesenta se publicaron muchísimas antologías de cuentos de cf, a menudo con más éxito que el que cabría imaginar ${ }^{18}$. Un caso significativo es el de Acervo, que publicó bastantes antologías a precios bastante altos para la época, con buena respuesta de los lectores. ${ }^{19}$ No fue un ejemplo aislado. La colección Géminis publicó cuatro antologías entre 1967 y 1968, que le llevaron a una mejor edición de otras diez con una estrecha periodicidad. Los lectores se surtieron también de cuentos de reconocido prestigio con las antologías de Bruguera: cerca de cuarenta entre 1971 y 1979.

Por consiguiente, si bien no se publicaron todas las grandes novelas de género, sí dispusimos de lo más importante de la cuentística del género en inglés. Y no solo se publicaron traducciones de

\footnotetext{
15 Tenemos algunos experimentos anteriores sin apenas influencia posterior ni reconocimiento de género, como La bomba increíble (Salinas, 1951), La nave (Salvador, 1959) o Corte de corteza (Sueiro, 1969). Incluso en el ejemplo de la novela de Salinas los estudiosos han evitado dicha vinculación (Moreno, 2006 y 2009).

${ }^{16}$ Distanciamiento de un problema real de la sociedad del autor (Suvin, 1979: 94).

${ }^{17}$ Hay que añadir que en la cf estos puntos de indeterminación (Iser 280-309) exigen una especial complementación a partir del campo referencial externo de la obra aportado por el lector (Harshaw, 1984: 130; Moreno, 2010: 173-7).

${ }^{18} \mathrm{El}$ éxito mediático no acompañó al comercial, puesto que era prácticamente imposible encontrar referencias en periódicos y revistas culturales de la época.

${ }^{19}$ Su antología número seis, por ejemplo, llegó a disfrutar de una tercera edición en 1966.
} 
los nombres más significativos, sino también de autores de escasísimo relieve con verdaderas obras maestras, como la antología No Time like the Future, de Nelson Bond (1959).

Se publicaron los mejores cuentos occidentales del género con unos estrechos márgenes de sincronía. La significativamente menor población española y sus escasos medios de distribución, unidos al poco éxito de las revistas de cuentos, favoreció que excelentes cuentos - premiados y constantemente reeditados en EE.UU. - llegaran mucho antes que las grandes novelas de los mismos escritores.

\subsection{El éxito oculto de los cuentos anglosajones: Nueva Dimensión}

Entre 1968 y 1983 se publicó la revista más longeva de cf en lengua española, Nueva Dimensión, que alcanzó los 148 ejemplares y 12 números extra. Además, obtuvo galardones internacionales como un "Special award to Nueva Dimensión for excellence in science fiction magazine production", otorgado en la $30^{\mathrm{a}}$ convención mundial de cf celebrada en Los Ángeles en 1972, y el "Specialized Professional Magazine" en la Eurocon I, celebrada en Trieste el mismo año. En realidad, Nueva Dimensión no fue nunca un negocio, sino un deseo de difundir la ciencia ficción en España (Santos, 1982: 424-425).

Los tres fundadores fueron Sebastián Martínez, Luis Vigil y el mencionado Santos. Sus objetivos fueron:

a) priorizar los cuentos

b) presentar material inédito

c) potenciar la cantera nacional

d) presentar corrientes de otras nacionalidades, sin menosprecio alguno

d) incluir artículos y ensayos

e) incluía una sección de noticias con novedades editoriales, cinematográficas y acontecimientos relevantes

f) publicar cartas al director, para propiciar el contacto con los lectores y favorecer el asociacionismo clásico de las revistas anglosajonas.

Durante sus quince años de vida, en Nueva Dimensión se diferenciaron dos etapas principales en relación con dos momentos históricos vividos en España. En primer lugar estaría la vivencia bajo la dictadura franquista y el control de la censura. Este momento se alargaría hasta finales de 1975. La segunda etapa fue paralela a la transición española, con la democratización y el crecimiento de libertades, como la de expresión. Esta permitió a los responsables de Nueva Dimensión una mayor apertura de temas y una ruptura de tabús morales, como explicaba Luis Vigil en editoriales del número 83, de noviembre de 1976, y del número 86, de febrero de 1977.

La primera etapa se centró, sobre todo, en la Edad de Oro anglosajona, aunque cumplieron con la búsqueda de material de diferentes nacionalidades. ${ }^{20}$

Los autores españoles de esta etapa constituyeron una primera generación autóctona, rescatada de antologías anteriores. Casi todos ellos estaban muy influidos por la cf de la Edad Dorada. Aparte de los responsables de la revista, otras firmas destacadas serían Juan García Atienza, el tándem español madre e hijo formado por Arturo Mengoti y María Guera, el doctor Alfonso Álvarez Villar o José Luis Garci, que compondrían el elenco del número 8, en febrero de 1969.

La segunda etapa disminuyó la distancia entre la fecha original de los cuentos y la de publicación en la revista, que no sería de más de diez años. En esta etapa final de la revista aumentó enormemente la cantidad y la calidad de los relatos españoles, así como la experimentación, apareciendo toda una nueva generación de autores. Algunos de ellos ya habían publicado en épocas anteriores, como Enrique Lázaro, y otros desarrollaron su obra principal tras la desaparición de la

\footnotetext{
${ }^{20}$ En el editorial del número 7, de enero de 1969, donde repasaron su primer año de existencia, se recuerda que de los sesenta y nueve relatos publicados, veintidós eran americanos, siete ingleses, trece españoles, cinco rusos, cuatro franceses y tres rumanos, amén de otras procedencias como Alemania, Uruguay, Canadá, Polonia, Suecia o Brasil.
} 
revista, como Rafael Marín o Javier Redal. En palabras de Domingo Santos: "La mayoría de los autores castellanos que hoy tienen un nombre en la cf española - excepto los últimos recién llegados, por supuesto - velaron sus armas en las páginas de Nueva Dimensión, y buen testigo de ello es la antología Lo mejor de la ciencia ficción española de Ediciones Martínez Roca, procedente casi en su totalidad de sus páginas" (422).

La revista tendió siempre hacia cierto conservadurismo, preocupada por contentar los dispares gustos del reducido público que la mantenía en funcionamiento, por lo que pocas veces se aventuraron a publicar relatos más innovadores y actuales si no venían acompañados de un predominio de autores o cuentos más tradicionales y con modelos narrativos más lineales o estandarizados. Así, los autores más publicados fueron: Isaac Asimov, Arthur C. Clarke, A. E. Van Vogt, Fred Hoyle, Eric Frank Russell y Robert Sheckley. Quizás las excepciones fueran Harlan Ellison y Philip K. Dick, dos hombres más innovadores que fueron del agrado del triunvirato editor, aunque no faltaron algunos conocidos relatos experimentales de Norman Spinrad, Roger Zelazny o Philip José Farmer.

Hay que destacar también su escaso interés por los productos de serie B que tanto han lastrado al género.

\subsection{El éxito oculto de los cuentos españoles: los fanzines}

El fanzine fue una publicación no profesional que surgió de los aficionados a la cf, pero que se extendió a otros campos, como la música, el cine, el cómic y la televisión. El primer fanzine, The Comet, fue publicado en Chicago en 1930. En España abundaron, sobre todo, los centrados en cómic y música alternativa. Su gran importancia en España es evidente por el gran número de ellos, aunque la crítica apenas los ha tomado en consideración hasta hace poco. ${ }^{21}$

Es imposible analizar aquí todos y cada uno de los fanzines que han ido probando fortuna a lo largo de las últimas cuatro décadas en España. Sus características, su calidad, sus objetivos... son tan variados como tipos de personas que se encontraban detrás de cada aventura editorial. Solo en el fondo bibliográfico de la Asociación Española de Fantasía, Ciencia Ficción y Terror se conservan más de doscientos títulos diferentes, de las cuales la mayoría son fanzines de cf publicados entre 1975 y 1995, con longevidades variadas.

De todos modos, podemos considerar que, en líneas generales, el fanzine era considerado una especie de "regalo": el esfuerzo de una o varias personas que perdían tiempo, energías e incluso dinero para ofrecer un producto con escasos o ningún beneficio económico. Hoy en día vivimos con este tipo de entrega personal gratuita gracias a internet. Sin embargo, las dificultades intrínsecas de los fanzines fueron mucho mayores que las de las actuales publicaciones en la red.

Por lo general, se trataba de ocho o diez hojas, que podían llegar a las treinta o cuarenta (salvo excepciones), con una maquetación muy sencilla y casi siempre reproducidos por ciclostiladoras, al principio, o por fotocopiadoras, según avanzaban los años ochenta. ${ }^{22}$ No era raro que los responsables no pasaran de los veinte o veinticinco años y que su formación editora fuera escasa o

\footnotetext{
${ }^{21}$ Destacamos como caso curioso un breve artículo en la revista Triunfo donde se expresa la admiración por el fenómeno, si bien centrada en los musicales; ver Tena (1982).

La dificultad para encontrarlos, especialmente los de cf, se evidencia en la hemeroteca de La Caixa Tarragona, que ha cuidado la búsqueda y catalogación de fanzines de todos los temas: http://www.hemeroteca.cat/busquedas/search.php?inMateriasField=Fanzines\&advanced=true. Apenas disponen de material de género, pero sí una considerable cantidad de fanzines dedicados a literatura alternativa, cómic y música rock.

22 En conversación personal, Juan Miguel Aguilera comenta que realizó ya un fanzine — Módulo- con Javier Redal mediante ciclostiladora (también conocidas como "vietnamitas") en 1977. Rafael Marín, en mensaje privado, asegura que su primer fanzine —Danger — lo publicó mediante fotocopias en 1975. Según él, las revistas contraculturales como Jaramago, de 1977, y de cómics como McClure, de 1978, fueron a multicopista y luego en offset. Manuel Barrero, investigador de cómic, afirma también en conversación personal que las fotocopiadoras comenzaron a popularizarse en 1975, aunque no hubo la gran explosión llegó a mediados de los ochenta. El primero español sobre tebeos sería de finales de los sesenta: Bang!, de 1968 , editado por Antonio Martín y Antonio Lara.
} 
nula. Sin embargo, el pobre acabado del material y la falta de experiencia eran acompañados de entusiasmo, trabajo, valentía y relaciones sociales. Por otro lado, representaron un excelente campo de prácticas para muchos de los editores actuales.

Algunos fanzines relevantes fueron Kandama (ocho entre 1980 y 1984, donde comenzaron varios de los escritores más relevantes del género en España), Maser (catorce entre 1980 y 1988), Tránsito (dieciocho entre 1982 y 1993), Gigamesh (que se haría revista hasta alcanzar cuarenta y cuatro números entre 1991 y 2007), el longevo BEM (setenta y cinco entre 1990 y 2000) y el importantísimo Zikkurath (veinte sumando sus dos épocas, entre 1975 y 1980), que pasaría como otros a revista y que aglutinaría mucha de la cultura underground del momento. Tomamos como ejemplo Kandama, por tratarse del fanzine en que, y $B E M$, por su extraordinaria longevidad.

Resultaron, sin duda, esenciales para la aparición del género en España. Por consiguiente, puede afirmarse que (de un modo muy "cienciaficcional") uno de los grandes impulsores de la explosión de 1 género en España fue la popularización de avances tecnológicos como la ciclostiladora y la fotocopiadora hacia 1975.

\section{Nudos geográficos e institucionales: Una influencia sociológica: el fándom}

Los escritores de cf no van a los congresos a vender sus libros, porque la gente que acude a ellos ya los ha comprado antes. Tampoco acuden a ser adulados por los lectores: precisamente estos suelen ser muy críticos con sus obras. Acuden a los congresos a escuchar conferencias, a coger ideas. La literatura convencional cambia cada cincuenta años; la de cf, cada cinco, y hay que estar muy al día (Orson Scott Card, citado por Martínez y BEM, 1998:12).

La explicación del fenómeno del fándom ha partido, de nuevo, del carácter intelectual del género:

La cf moderna se describe mejor como un género que tiene una larga conversación continua consigo mismo. Los escritores se conocen unos a otro, escriben en respuesta de unos a otros y así es como evoluciona. Eso no es cierto en otros géneros. Por supuesto, se influyen unos a otros, pero no están tan unidos. Por ejemplo Raymond Chandler se encontró con Dashiel Hammet solo una vez en una cena, hay una foto, y vivían en el mismo estado y en la misma ciudad. Los escritores de novelas del oeste nunca se conocían y los de misterio rara vez lo hacen. Supongo que en parte se debe a que la cf tiene tantas ideas que se puede hablar sobre estas. En cierta forma es muy difícil hablar sobre novelas de misterio porque no tienen ideas, tienes estilos. Pero las ideas son más fáciles de comunicar, que es la razón por la que la cf es una literatura internacional (Gregory Benford, citado por Barceló y BEM, 1993: 10).

"Fándom" es una derivación del término inglés "fan": el aficionado a algo. "Dom" viene a asimilar el término con otros vocablos ingleses como "kingdom". "Fándom" designa, por tanto, "el territorio de los fans", la semiosfera de personas que se relacionan a través del ámbito de la cf de manera no obligadamente profesional. La diferencia entre estos aficionados a la cf y los aficionados a cualquier otro género consiste tanto en su organización como en su influencia en la misma producción literaria, así como en el análisis y la edición de las obras (ver Reid, 2009).

Su influencia en la cf española de los ochenta y los noventa fue enorme por el crecimiento del número de asociaciones, convenciones, tertulias y premios literarios que aparecieron en numerosas ciudades.

Entre las asociaciones, destaca la Asociación Española de Fantasía, Ciencia Ficción y Terror (AEFCFT), creada en 1990. Ha llegado a agrupar a cientos de aficionados, "mantiene un archivo o fondo bibliográfico de publicaciones del género o relacionadas con el mismo, con la intención de que se constituya como una base de estudio y consulta" (Cuevas y Pallarés, 2003: 9-10). Además, 
mantiene listas de correo electrónico y colabora en ocasiones con los distintos actos que puedan celebrarse en España.

En cuanto a los premios, se trata de una de las principales fuentes de difusión del género. El más prestigioso de la cf española sería el Ignotus, equivalente al Hugo estadounidense y concedido en las convenciones anuales o "hispacones" por votación popular. Existen numerosas categorías y ha sido acusado múltiples veces en foros, listas de correo y blogs por su supuesto populismo.

Otros concursos literarios fueron numerosos y sirvieron como plataforma de lanzamiento para jóvenes autores. Algunos de los concursos y premios españoles más importantes han sido —además del Ignotus - : el UPC, el Xatafi-Cyberdark, el UPV, el Alberto Magno, el Domingo Santos, el Celsius y el Minotauro, aunque en 2013 ya han desaparecido muchos de ellos.

Otra seña de identidad son las tertulias literarias. Estas reuniones periódicas de aficionados representaron el fenómeno más popular dentro de la cf española en la década de los noventa, en ciudades como Madrid, Barcelona, Gijón, Bilbao, Vitoria, Santiago de Compostela, Vigo, Sevilla, Valencia y Zaragoza. Su éxito se debió a un carácter más abierto y flexible que el de las asociaciones, así como a la inexistencia de cargas burocráticas (Cuevas y Pallarés, 2003: 19).

En cuanto a las convenciones, la principal española se llama HispaCón y se celebra anualmente desde hace más de treinta años. Cambia su sede de una ciudad a otra para comodidad de los aficionados. La primera tuvo lugar en 1968. Las siguientes fueron en 1969, 1970, 1975, 1978, 1979, 1980 y se han celebrado ya ininterrumpidamente desde 1991. Los invitados no suelen recibir dinero; ni siquiera los escritores de renombre, aunque sí suele haber algún invitado honorífico (nacional o extranjero) al que se le pagan el viaje y la estancia con el dinero de las inscripciones.

Las conferencias son seleccionadas tanto por el currículum del conferenciante como por el interés del tema. Las HispaCones no se limitan a la cf, sino que se extienden más allá de su ámbito. Sin embargo, no puede negarse que la cf fue durante años el verdadero punto central del evento, aunque en los últimos años han derivado a la fantasía heroica y el terror.

Como puede apreciarse, el dinamismo durante los años ochenta y, especialmente, los noventa fue tan fuerte que existía un grupo de varios cientos de aficionados en contacto más o menos permanente que consumían los productos que ellos mismos escribían y editaban. Esto produjo una fuerte endogamia, muy beneficiosa para el sentimiento de grupo, la vitalidad del mismo y su mantenimiento, pero muy perjudicial para su crecimiento, tanto literario como editorial.

\section{Conclusiones}

Hemos realizado un largo recorrido: desde las primeras traducciones de la cf en España en los años cincuenta hasta su consolidación en la segunda mitad de los ochenta y durante los noventa.

En un primer momento, cabría pensar que el cambio socio-político desarrollado durante la transición española pudo influir en su desarrollo. Sin embargo, no podemos afirmar que ese fuera el principal motivo. Por el contrario, influyeron factores muy diversos.

Como hemos visto, Nueva Dimensión, con una sección dinámica de correo de los lectores, al estilo anglosajón, fue decisiva.

Casi al mismo tiempo se produjo una explosión de fanzines, animados por una constatable tradición de antologías publicadas ininterrumpidamente desde los años cincuenta. La aparición de tecnología al alcance del público general fue determinante en este sentido. Con ello, no solo se accedía a abundante material y se favorecía el ánimo explorador de jóvenes editores, sino que también muchos escritores pudieron publicar sus primeros relatos, con el correspondiente intercambio de opiniones con los lectores.

El fenómeno de los fanzines favoreció también la proliferación de eventos como las tertulias y las convenciones, que favorecieron la aparición y desarrollo de nuevos escritores.

Cabe suponer que el cine de cf pudo influir, pero no tenemos constancia de que acelerara el proceso en nuestro país como sí lo hizo en EE.UU. Sus temas y sus personajes apenas aparecen en los relatos españoles de cf. Si influyó, debió de ser de un modo general o en un público entregado, 
pero desde luego no se detectan influencias directas. Solo los bolsilibros muestran temas y personajes similares, pero su decadencia coincide precisamente con esos años, por lo que casi cabe afirmar que la difusión de la space opera apenas fue determinante.

Por el contrario, sí podemos encontrar una clara influencia de la New Wave, cuyos cuentos llegaron a España inmediatamente; seguidos, a mitad de los setenta, por sus novelas. Podemos encontrar formas experimentales, temas y personajes cercanos a esta tendencia en novelas como Consecuencias naturales (E. Barceló, 1994) o La sonrisa del gato (Martínez, 1995).

Ante todo, la principal característica será este nuevo interés por la poetización del género, tan New Wave, que separaba a los jóvenes autores de la maquinaria de los bolsilibros.

$\mathrm{Si}$ a todo esto unimos los vaivenes editoriales de fugaces nacimientos y decadencias de nuevas editoriales, con sus correspondientes saldos, encontramos una serie de factores que favorecían el surgimiento de una generación de autores interesados por la cf más literaria.

Sin embargo, descubrimos también con todo ello que todos estos factores se desarrollaban al margen de la literatura canónica española y del mundillo editorial más fuerte de la época. Sin duda, este hecho propició la formación de un cómodo y perjudicial gueto (M. Barceló, 1990: 22).

Por consiguiente, encontramos suficientes factores sociales y editoriales para entender el surgimiento de un movimiento literario de cf en España entre 1985 y 2000. También podemos apreciar algunos de los motivos que impidieron que no proliferase en etapas anteriores y quedara reducida a un círculo poco relevante, aunque mucho más amplio de lo que se pensaba hasta ahora.

Todo ello demuestra que existía un profundo interés por una literatura alternativa en España durante los años ochenta y noventa. E incluso podemos encontrar antes este interés, si nos fijamos en el éxito de las antologías de relatos. No obstante, la crítica ignoró este hecho, aunque desdecía el mito de una España centrada en una literatura extremadamente realista y poco interesada por lo científico o por las sociedades alternativas.

Queda mucho por estudiar en cuanto al impacto de esta literatura en la sociedad y en cuanto a la manera en que fue vivida por sus protagonistas. Y, pese a algunos conatos, queda también la compleja tarea de catalogar todos estos fondos, rescatarlos de su más que posible desaparición y, con ello, escribir una historia de la literatura española contemporánea más completa que las propuestas hasta el momento.

\section{Bibliografía}

\section{Ficción:}

Aguilera, Juan Miguel, y Redal, Javier (1998). Mundos en el abismo. Barcelona, Ultramar.

ANTOLÍn RATO, Mariano (1981): «El alma del robot», Zikkurath. núm. 2, pp. 55-56.

Aute, Luis Eduardo (1982): «Morir de viejo», en Domingo SANTOS (ed.). Lo mejor de la ciencia ficción española. Barcelona, Martínez Roca, pp. 71-76.

BALlARD, James Graham (1973): Crash. Londres, Vintage. 1. ${ }^{a}$ ed. esp.: Crash. Francisco Abelenda (trad.). Barcelona, Minotauro, 1979. Últ. ed. esp.: Crash. Francisco Abelenda (trad.), Barcelona, Minotauro, 2012.

BARCELÓ, Elia (1991): «La estrella», en Fernando Ángel MoRENo (ed.). Prospectivas: Antología del cuento de ciencia ficción española actual. Madrid, Salto de Página, 2012, pp. 69-92. (1994): Consecuencias naturales. Madrid, Miraguano.

BARCELÓ, Miquel (1990): Ciencia ficción: Guía de lectura. Barcelona, Ediciones B.

BERMúdeZ CASTILlo, Gabriel (1976): Viaje a un planeta Wu-Wei. Barcelona, Acervo.

Bester, Alfred (1956): The Stars My Destination. Londres, Sidgwick\&Jackson. 1. a ed. esp.: Las estrellas, mi destino. Sebastián Martínez (trad.), Barcelona, Dronte, 1970. Últ. esp.: Las estrellas mi destino. Cristina Macía y Sebastián Martínez (trads.), Barcelona, Gigamesh, 1999. 
Bond, Nelson (1959): No Time Like the Future. Nueva York, Avon. 1. a ed. esp.: Ningún tiempo como el futuro. [Desconocido (trad.)], Barcelona, Edhasa, 1959. Últ. ed. esp.: Ningún tiempo como el futuro. [Desconocido (trad.)], Barcelona, Edhasa, 1966.

BRUNNER, John (1964): The Whole Man. Nueva York, Ballantine Books. 1. a ed. esp.: El hombre completo. Antonio Ribera Jordá (trad.), Barcelona, Edhasa, 1967. Últ. ed. esp.: El hombre completo. Antonio Ribera Jordá (trad.), Madrid, La Factoría de Ideas, 2012.

Clarke, Arthur C. (1956). The City and the Stars. Londres, Frederick Muller. ${ }^{\mathrm{a}}$. ed. esp.: La ciudad y las estrellas. Francisco Cazorla Olmo (trad.), Barcelona, Edhasa, 1967. Últ. ed. esp.: La ciudad y las estrellas. Julián Díez (trad.), Madrid, Alamut, 2013.

Dick, Philip K. (1955): Solar Lottery. Londres, Ace Books. 1. ${ }^{\text {a }}$ ed. esp.: Lotería solar. Mariano Orta Manzano (trad.), Barcelona, Cenit, 1960. Últ. ed. esp.: Lotería solar. Manuel Figueroa y Marcelo Tombetta (trads.), Barcelona, Minotauro, 2012.

(1962): The Man in the High Castle. Chicago, Putnam. 1. ${ }^{a}$ ed. esp.: El hombre en el castillo. Manuel Figueroa (trad.), Barcelona: Minotauro, 1974. Últ. ed. esp.: El hombre en el castillo. Manuel Figueroa (trad.), Barcelona, Minotauro, 2011.

(1969): Ubik. Nueva York, Doubleday. 1. ${ }^{a}$ ed. esp.: Ubik. Manuel Espín (trad.), Barcelona, Martínez Roca, 1976. Últ. ed. esp.: Ubik. Manuel Espín (trad.), Barcelona, 2012.

Herbert, Frank (1965): Dune. Philadelphia y Nueva York, Chilton Books. 1. a ed. esp.: Dune. Domingo Santos (trad.), Barcelona, Acervo, 1975. Últ. ed. esp.: Dune. Domingo Santos (trad.), Madrid, La Factoría de Ideas, 2012.

LE Guin, Ursula K. (1969): The Left Hand of Darkness. Nueva York, Ace Books. 1. a ed. esp.: La mano izquierda de la oscuridad. Francisco Abelenda (trad.), Barcelona, Minotauro, 1973. Últ. ed. esp.: La mano izquierda de la oscuridad. Francisco Abelenda (trad.), Barcelona, Minotauro, 2009.

LEM, Stanislaw (1961). Solaris, Varsovia, Mom. 1. a ed. esp.: Solaris. Matilde Horne (trad. del inglés), Barcelona, Minotauro, 1977. Últ. ed. esp.: Solaris. Joanna Orzechowska (trad.), Madrid, Impedimenta, 2011.

(1957). Dzienniki gwiazdowe, Varsovia, Iskry. 1. a ed. esp.: Diarios de las estrellas. Viajes, Jadwiga Maurizio (trad.), Barcelona, Bruguera, 1978. Últ. ed. esp.: Diarios de las estrellas, Jadwiga Maurizio (trad.), Madrid, Alianza, 2013.

MALlORQUí, César (1993). «El rebaño», en Fernando Ángel MoReno (ed.). Prospectivas: Antología del cuento de ciencia ficción española actual. Madrid, Salto de Página, 2012. pp. 27-68.

MARín, Rafael (1982): Lágrimas de luz. Barcelona, Gigamesh, 2002.

MARTíneZ, Rodolfo (1995): La sonrisa del gato. Gijón, Sportula, 2012.

MCCARThY, Cormac (2006): The Road. Nueva York, Alfred A. Kopf, 2006. 1. ${ }^{\circ}$ ed. esp. La carretera. Luis Morillo Fort (trad.), Barcelona, Mondadori, 2007.

SAlinAS, Pedro (1951): La bomba increíble: Una fabulación. Madrid, Viamonte, 1997.

SALVADOR, Tomás (1959): La nave. Córdoba, Berenice, 2005.

SANTOS, Domingo (ed.) (1982): Lo mejor de la ciencia ficción española. Barcelona, Martínez Roca.

Strugatski, Arkadi y STRUGATSKI, Boris (1972). «Picnic na obochine», Avrora, núm. 7, pp. 28-43; núm. 8, pp. 38-51; núm. 9, pp. 38-51; núm. 10, pp. 42-51. 1. ${ }^{\text {a }}$ ed. esp.: Pícnic extraterrestre. Edith Zilli (trad.), Buenos Aires, Emecé, 1977. Últ. ed. esp.: Pícnic junto al camino. Miquel Barceló (trad. del inglés), Barcelona, Ediciones B, 2001.

SueIro, Daniel (1969): Corte de corteza. Madrid, Salto de Página, 2012.

VILLENA, Luis Antonio de (1978): «Flores de máquina», Zikkurath 2000. núm. 2015, pp. 60-62.

VV.AA. (1964): Antología de novelas de anticipación IV. Barcelona, Acervo.

— (1965): Antología de novelas de anticipación V. Barcelona, Acervo.

(1966): Antología de novelas de anticipación VI. Barcelona, Acervo.

(1967): Antología de novelas de anticipación VII. Barcelona, Acervo. 
Condiciones para el nacimiento de la ciencia ficción española contemporánea

\section{No ficción:}

ANÓNIMO (1978). «Aumenta el interés de escritores y lectores por la literatura de ciencia ficción», $E l$ País, 9 de diciembre.

BARBERÁN, Rafael y GiMENO, Ángels (2002) «El imperio de los superventas», en VV.AA. La ciencia ficción española. Madrid, Robel, pp. 165-175.

BARCELó, Miquel (1990): Guía de lectura, Barcelona, Ediciones B.

BARCELÓ, Miquel y BEM (1993): «Paisaje en el tiempo: Entrevista con Gregory Benford», en BEM. Núm. 53, pp. 10-15.

BEHM, Florence (1993): La ciencia ficción en España. [Desconocido], AEFCF.

Bloom, Harold (1994): The Western Canon: The Books and School of the Ages. Nueva York, Harcourt Brace. Ed. Esp.: Damián Alou (trad.), Barcelona, Anagrama, 1995.

CABAlleR, José (2002): «Larry Winters, alias José Caballer», en: VV.A. La ciencia ficción española. Madrid, Robel, pp. 199-204.

Canalda, José Carlos (2001): Luchadores del espacio: una colección mítica de la C.F. española. Madrid, Río Henares.

CANalda, José Carlos y CANTERo URIBE-EcheVerria, Igor (2002a): «Las colecciones de ciencia ficción popular en España (1950-1990)», en VV.AA. La ciencia ficción española. Madrid, Robel, pp. 67-93.

(2002b): «Escritores de novela de a duro: Los grandes desconocidos de la ciencia fícción española», en VV.AA. La ciencia ficción española. Madrid, Robel, pp. 95-109.

Cuevas, Javier y PAllarés, José Miguel (2003): Guía de la ciencia ficción española. Madrid, Robel.

DíEZ, Julián (1998a): «Las colecciones de cf (I): Nueva Dimensión», Gigamesh. Núm. 14, pp. 22-25.

— (1998b): «Las colecciones de cf (II): Nebulae, primera época», Gigamesh. Núm. 15, pp. 39-43.

(1998c): «Las colecciones de cf (III): Edaf, Albia, Erus», Gigamesh. Núm. 16, pp. 40-43.

(1998d): «Las colecciones de cf (IV): Bruguera», Gigamesh. Núm. 17, pp. 40-43.

(1999a): «Las colecciones de cf (V): Nebulae, segunda época», Gigamesh. Núm. 18, 36-8.

(1999b): «Las colecciones de cf (VI): Super Ficción», Gigamesh. Núm. 19, pp. 41-4.

(1999c): «Las colecciones de cf (VII): Acervo», Gigamesh. Núm. 20, p. 41.

(1999d): «Las colecciones de cf (VIII): Ultramar», Gigamesh. Núm. 21, pp. 39-42.

(1999e): «Las colecciones de cf (IX): Destino, Edaf, Júcar», Gigamesh. Núm. 22, pp. 39-42.

(2000a): «Las colecciones de cf (X): Minotauro Argentina». Gigamesh. Núm. 23, pp. 35-37.

(2000b): «Las colecciones de cf (XI): Gran Super Ficción», Gigamesh. Núm., 24, pp. 37-39.

(2000c): «Las colecciones de ciencia ficción (XII): Miraguano», Gigamesh. Núm. 27, pp. 3839.

(2001): «Las colecciones de cf (XII): Adiax y Arcadia», Gigamesh. Núm. 29, pp. 38-40.

(2003): «Ciencia ficción española: una análisis en perspectiva», en Julián DíEZ (ed.). Antología de la ciencia ficción española 1982-2002. Barcelona, Minotauro, pp. 9-29.

DíEZ, Julián, y MORENO, Fernando Ángel (2014): Historia y antología de la ciencia ficción española. Madrid, Cátedra.

ESCRIG, José Antonio (2005). «Escenarios del debate sobre la historia literaria», en Luis BELTRÁN AlMERÍa y José Antonio EsCRIG (eds.), Teorías de la historia literaria. Madrid, Arco/Libros, pp. 23-44.

FERRERAS, Juan Ignacio (1972): La novela de ciencia ficción. Madrid, Siglo XXI.

GrEenblatt, Stephen (1997): «What is the History of Literature?», Critical Inquiry, núm. 23, pp. 460-481. Ed. Esp.: «¿Qué es la historia literaria?», en Luis BELTRÁN ALMERÍA, Luis y José Antonio EsCRIG. Teorías de la historia literaria. Manuel Asín (trad.), Madrid, Arco/Libros, 2005, pp. 91-121.

GuILlÉN, Claudio (1989): «De influencias y convenciones», en Claudio GuILLÉN. Teorías de la historia literaria. Madrid, Espasa Calpe, pp. 95-117. 
HARSHAW, Benjamin (1984): «Fictionality and Fields of Reference. Remarks on a Theoretical Framework», Poetics Today. Vol. 5, núm. 2, pp. 227-51. Ed. Esp.: «Ficcionalidad y campos de referencia», en Antonio GARRIDO DOMíngUEZ (ed.). Teorías de la ficción literaria, Eugenio Contreras (trad.), Madrid, Arco/Libros, pp. 123-157.

ISER, Wofgang (1976): Der Akt des Lesens. Theorie ästhetischer Wirkung. Uni-Taschenbücher, 636, Literaturwissenschaft, Munich, Fink. Ed. Esp.: El acto de leer. Manuel Barbeito (trad.), Madrid, Taurus, 1987.

JAUSS, Hans Robert (1991): Ästhetische Erfahrung und literarische Hermeneutik, Frankfurt am Main, Suhrkamp. Ed. Esp.: Experiencia estética y hermenéutica literaria. Jaime y Ela $\mathrm{M}^{\mathrm{a}}$ Fernández Palacios (trads. [parcial]), Madrid, Taurus, 1986.

KNICKERBOCKER, Dale (2000): «Technology, Technophobia and Gynophobia in Gonzalo Torrente Ballester's Quizá nos Ileve el viento al infinito», Journal of the Fantastic in the Art. Núm. 10, pp. 353-371.

(2004): «Apocalypse and Alienation in Javier Negrete's Nox perpetua», Journal of the Fantastic in the Arts. Núm. 15, pp. 288-308.

(2008): «Science, Religion and Indeterminacy in Juan Miguel Aguilera's La locura de Dios (The Folly of God)», Foundation. Vol. 37, núm. 102, pp. 31-48.

LE GuIN, Ursula K. (1989). «On The Left Hand of Darkness and The Dispossessed», en Ben BovA (ed.). The Best of the Nebulas. Nueva York, Tor Books, pp. 20-21. Ed. esp.: «Sobre La mano izquierda de la oscuridad y Los desposeídos», en Ben BovA (ed.). Lo mejor de los premios Nebula. Paula Tizzano, Márgada Averbach y María Cristina Pinto (trads.), Barcelona, Ediciones B, 1994, pp. 47-49.

Lotman, Iuri. «O semiosfere», en Semeiotiké. Trudy po znakovym sistema. Núm. 17, pp. 5-23. Ed. Esp.: «Acerca de la semiosfera», en: Iuri LotMAN. La semiosfera I. Desiderio Navarro (trad.), Madrid, Cátedra, 1996, pp. 21-42.

LuCKHURST, Roger (2005): Science Fiction, Cambridge, Polity.

MARTín RodRíGUEZ, Mariano (2009a): «La literatura especulativa de Agustín de Foxá», en Agustín DE FoXÁ. Historias de ciencia ficción: Relatos, teatro, artículos. Madrid, La biblioteca del Laberinto, pp. 7-93.

(2009b): «Géneros futuros: visiones de la mujer y las relaciones amorosas en sentimental club (1909), de Ramón Pérez de Ayala», en Pilar NIEVA DE LA PAZ (ed.). Roles de género y cambio social en la literatura española del siglo XX. Amsterdam, Rodopi, pp. 265-280.

- (2010): «Science Fiction as Mainstream Literatura: The Spanish Scientific Romance and its Reception before The Spanish Civil War», Foundation. Vol. 39, núm.110, pp. 38-59.

MARTínEZ, Rodolfo y BEM (1998): «Contar sencilla y originalmente: Entrevista con Orson Scott Card». BEM. Núm. 64, pp. 12-14.

MENDLESOHN, Farah (2009): «Fiction, 1926-1949», en: Mark Bould, Andrew M. ButLer, Adam ROBERTS y Sherryl Vynt (eds.). The Routledge Companion to Science Fiction. Londres y Nueva York, Routledge, pp. 52-61.

Mengs, Antonio (2004): Stalker, de Andrei Tarkovski. Madrid, Rialp.

MERElo, Alfonso (2001): [Prólogo], en José Luis CANALDA. Luchadores del espacio: una colección mítica de la C.F. española. Madrid, Río Henares, pp. 9-13.

Molina-Gavilán, Yolanda (2002): Ciencia ficción en español: una mitología moderna ante el cambio. Nueva York, The Edwin Mellen Press.

MoRENO, Fernando Ángel (2006): «Recursos genéricos de la novela de ciencia ficción de Pedro Salinas», en Tropelías: Revista de Teoría de la Literatura y Literatura Comparada. Núm. 1517, pp. 411-421.

(2009): «Repercusiones literarias de La bomba increíble, de Pedro Salinas», Per Abbat. Núm. 9, pp. 115-122. 
— (2010): Teoría de la literatura de ciencia ficción: Poética y retórica de lo prospectivo. Vitoria, PortalEditions. Nueva ed. ampliada: Gijón, Sportula, 2013.

Pulido TiRADO, Genara (2004): «La especulación científica en literatura. Para una teoría de la narrativa de ciencia ficción», Discurso: Revista internacional de semiótica y teoría literaria. Núm. 18, pp. 27-48.

ReID, Robin Anne (2009): «Fan Studies», en: Mark Bould, Andrew M. ButLeR, Adam RoberTs y Sherryl Vynt (eds.). The Routledge Companion to Science Fiction. Londres y Nueva York, Routledge, pp. 204-213.

SÁNCHEZ-CONEJERO, Cristina (2009): Novela y cine de ciencia ficción española contemporánea. Nueva York, The Edwin Mellen Press.

SANTIAGO, Juan Manuel (2009): «La ciencia ficción española en 1991», Pornografía emocional [en línea]. [Ref. 15 de mayo de 2016]. Disponible en internet <http://juanmasantiagoblog.blogspot.com.es/2009/11/hacia-el-infinito-y-mas-alla-laciencia.html>.

SAwYer, Andy (2009): «Space Opera», en Mark Bould, Andrew M. Butler, Adam Roberts y Sherryl Vynt (eds.). The Routledge Companion to Science Fiction. Londres y Nueva York, Routledge, pp. 505-509.

SCHOLES, Robert y RABKIN, Eric (1977): Science fiction: History. Science. Vision. Nueva York, Oxford UP. Ed. esp.: La ciencia ficción: Historia. Ciencia. Perspectiva. Remigio Gómez Díaz (trad.), Madrid, Taurus, 1982.

Suvin, Darko (1979): Memorphoses of Science Fiction: On the Poetics and History of a Literary Genre. New Haven y Londres, Yale UP. Ed. esp.: Metamorfosis de la ciencia ficción. Sobre la poética y la historia de un género literario. Federico Patán López (trad.), México, Fondo de Cultura Económico, 1984.

TARANCÓN GIMENO, Jorge (2002): «Catálogo-selección de colecciones de ciencia fícción española», en VV.AA. La ciencia ficción española. Madrid, Robel, pp. 451-509.

TENA, Agustín (1982): «El fanzine en España: ¿Vanguardia o panfleto?», Triunfo. Núm. 21-22, pp. 48-49.

VALDÉS SAN MARTín, Mario J. (2002): «Rethinking the History of Literary History», en Linda HutCHEON y Mario J. VALDÉs (eds.). Rethinking Literary History: A Dialogue on Theory. Nueva York, Oxord UP, pp. 63-115. Ed. esp.: «Historia de las culturas literarias: Alternativa a la historia literaria», en Luis BELTRÁN ALMERÍA y José Antonio ESCRIG (eds.). Teorías de la historia literaria. Madrid, Arco/Libros, 2005, pp. 123-218.

VERA RAMÍREZ, Antonio (2002): «Lo fantástico de la fantasía», en VV.AA. La ciencia ficción española. Madrid, Robel, pp. 177-197. 